\title{
Phytopharmaceuticals - The Future Prospects and Economy Driver
}

\section{Rajesh Singla*}

Associate Professor, Microbiology and Head, Agriculture Department, S.S.D. College of Professional Studies, Punjab, India

*Corresponding Author: Rajesh Singla, Associate Professor, Microbiology and Head, Agriculture Department, S.S.D. College of Professional Studies, Punjab, India.

Received: November 22, 2019; Published: November 29, 2019

DOI: $10.31080 /$ ASPS.2019.03.0450

Keywords: Phyto-Pharmaceuticals; Secondary Metabolites; Nanophytomedicine; Industry Economy

Extreme Dependence as well as misuse of antibiotics has led to the search for new as well as more effective and safe treatment methods during the last decade. The most reliable source is the plants which have a rich reservoir of active antimicrobial agents called phyto-pharmaceuticals. Phyto-pharmaceuticals are natural products (secondary metabolites) of plant origin which exclusively contain one or more substances as active ingredients or a may be a combinations of them. Their effectiveness depends on the pharmacologically active ingredients that interact with protein structures called drug targets (receptors, enzymes and transport systems) in the human body. Some important phyto-pharmaceuticals are flavonoids, isoflavonoids, terpenoids, anthocyanidins, carotenoids, lycopenes, polyphenols, omega-3 fatty acids, phytosterols etc. These substances have antimicrobial, anti-inflammatory, antioxidant, antiallergic, antidiabetic and many other therapeutic effects. Phytopharmaceuticals also holds exciting opportunities for the food industry by creating novel food products which contains bioactive components. Through genetic engineering these can be added or their level can be increased in the traditional food and can add value to it for example genetically modified tomato with high lycopene content will have very high antioxidant activity. Nanophytomedicine is latest amongst the new approach of administration and use of plant based phytomedicines which is knocking over the door of plethora of new antimicrobials and opportunities in phytopharmaceutical industry. Nanophytomedicine not only improves the bioavailability as well as efficacy of the drug administered but also decreases the toxicity and side effects if any to the person concerned. It has proved beneficial in various treatments including cancer and has entered into the cosmetic industry too whereby nanoparticles have proved to be safe and effective in skin care formulations thereby reducing the harmful effects of ultraviolet radiations which leads to skin cancer.

The amount of these phytopharmaceuticals entering into the global market is ever increasing and the demand has risen due to its increased acceptance by the people owing to its benefits.

The need of the hour is that various government agencies play an important role in providing facilities as well as encouraging those involved in preparing and proving herbal drugs and brings them to a common platform along with some incentive schemes for the industry which may act as a driving force for the development of phytopharmaceutical industry. Also, the marketing of these phytopharmaceuticals is very important so as to uplift the interest as well as develop the taste of the consumers. The future of phytopharmaceuticals is very bright as far as commercial viability is concerned and it will certainly create jobs and boost the economy of the country.

\section{Volume 3 Issue 12 December 2019 (C) All rights are reserved by Rajesh Singla.}

